\title{
Methylation and ovarian cancer: Can DNA methylation be of diagnostic use? (Review)
}

\author{
JULIE L. HENTZE ${ }^{1}$, CLAUS K. HØGDALL ${ }^{2}$ and ESTRID V. HØGDALL ${ }^{1}$ \\ ${ }^{1}$ Department of Pathology, Herlev Hospital, University of Copenhagen, 2730 Herlev; ${ }^{2}$ Department of Gynecology, \\ The Juliane Marie Centre, Rigshospitalet, University of Copenhagen, 2100 Copenhagen, Denmark
}

Received July 2, 2018; Accepted December 4, 2018

DOI: $10.3892 /$ mco.2019.1800

\begin{abstract}
Ovarian cancer is a silent killer and, due to late diagnosis and frequent chemo resistance in patients, the primary cause of fatality amongst the various types of gynecological cancer. The discovery of a specific and sensitive biomarker for ovarian cancer could improve early diagnosis, thereby saving lives. Biomarkers could also improve treatment, by predicting which patients will benefit from specific treatment strategies. DNA methylation is an epigenetic mechanism, and 'methylation imbalance' is characteristic of cancer. Previous research suggests that changes in DNA methylation can be used diagnostically, and that they may predict resistance to treatment. This paper gives an up-to-date overview of research investigating the potential of DNA methylation-based markers for diagnostics, prognostics, screening and prediction of drug resistance for ovarian cancer patients. DNA methylation cancer-biomarkers may be useful for cancer treatment, particularly since they are chemically stable and since cancer-associated changes in methylation typically precedes tumor growth. DNA methylation markers could improve diagnosis and treatment and might even be used for screening in the future. Furthermore, DNA methylation biomarkers could facilitate the development of precision medicine. However, at this point no biomarkers for ovarian cancer have a sufficient combination of sensitivity and specificity in a clinical setting. A reason for this is that most studies have focused on a single or a few methylation sites. More large screenings and genome-wide studies must
\end{abstract}

Correspondence to: Professor Estrid V. Høgdall, Department of Pathology, Herlev Hospital, University of Copenhagen, Herlev Ringvej 75, 2730 Herlev, Denmark

E-mail: estrid.hoegdall@ regionh.dk

Abbreviations: OC, ovarian cancer; FIGO, International Federation of Gynecology and Obstetrics; RMI, risk of malignancy index; MSP, methylation-specific PCR; miRNA, microRNA; MESC, methylated in embryonic stem cells; OS, overall survival; PFS, progression free survival

Key words: ovarian cancer, diagnostic/prognostic biomarkers, prediction of chemo-resistance, DNA methylation, precision medicine be performed to increase the chance of identifying a DNA methylation marker which can identify ovarian cancer.

\section{Contents}

1. Introduction

2. DNA methylation in cancer

3. DNA methylation profiles as biomarkers

4. Methods for detection of methylation

5. DNA hypermethylation in OC

6. DNA hypomethylation in $\mathrm{OC}$

7. Potential of DNA methylation in OC diagnostics

8. Potential of DNA methylation in OC prognostics

9. DNA methylation profiles as markers for OC screening

10. DNA methylation and the prediction of chemo-resistance

11. Discussion

\section{Introduction}

The leading cause of death from gynecological malignancy is ovarian cancer (OC) (1). With a 5-year survival rate of only $52 \%$, OC is the 5th most common killer amongst cancers in women (1-3). More than $60 \%$ of the patients are diagnosed at a late stage [stage III/IV, International Federation of Gynecology and Obstetrics (FIGO)], resulting in high mortality $(1,2,4,5)$. The 'risk of malignancy index' (RMI) is used to identify women with a pelvic mass and a high risk of OC $(6,7)$. RMI includes serum levels of the biomarker CA125 in addition with ultrasound scanning and menopausal state of the patient. Neither CA125 alone nor RMI are optimal for selecting women at high risk of $\mathrm{OC}$, and new more sufficient $\mathrm{OC}$ markers for use in diagnostics or screening programs are highly desired to improve survival (8-14). Another way to improve survival could be treatment using biological, targeted drugs based on identification of predictive biomarkers, as approximately $80 \%$ of OC patients develop resistance towards platinum-based treatment (15).

Gene expression can be robustly changed by the process of DNA methylation (16). DNA methylation is a process where methyl-groups are added to the nucleotide cytosine. The methyl-group is normally added to a cytosine followed by a guanine, called a $\mathrm{CpG}$ site. Methylation has several functions, including stabilization of the DNA molecule and regulation 
of gene transcription. The regulatory function of DNA methylation is essential in several processes of embryonal development $(17,18)$. Altered DNA methylation, resulting in chromosome instability and changed gene expression, has been highly correlated to carcinogenesis. Because of the involvement of methylation in cancer, methylation profiles have potential as biomarkers. This review aims at summarizing the current knowledge of the role of DNA methylation in OC and the clinical potential of DNA methylation patterns as OC biomarkers for diagnostics, screening and prediction of drug response.

\section{DNA methylation in cancer}

One of the earliest proofs that erroneous DNA methylation is directly involved in carcinogenesis came in 1994, when Herman et al showed that the tumor suppressor gene VHL might be silenced by hypermethylation of its promotor in some cases of renal carcinomas (19). Since then, numerous similar studies has shown that promotor hypermethylation is a widespread mechanism for silencing of tumor suppressor genes in human cancers, and it is estimated to be as common as mutation $(20,21)$. Cancer related DNA methylation is often observed earlier than the actual neoplastic transformation, and it has been suggested that DNA methylation is a primary link between environment and cancer, as there seems to be a connection between lifestyle and cancer related DNA methylation in un-symptomatic persons $(22,23)$. It is therefore also likely, that DNA methylation is the initiator of tumor formation in a high percentage of cancer-cases.

The best understood way in which DNA methylation affects carcinogenesis is by silencing of tumor suppressors by localized hypermethylation in promoters and other regulatory areas, apparently caused by increased levels of DNA methyltransferase $(24,25)$. Aberrant methylation however, can also lead to cancer in other ways. Reduced methylation of oncogene promoters has been observed in numerous cancers $(26,27)$. Another very widespread mechanism is chromosome instability, caused by genome wide hypomethylation (28-30).

\section{DNA methylation profiles as biomarkers}

DNA methylation has several advantages compared to other molecular markers. Already in 1999, it was discovered that cancer related DNA methylations can be measured in the serum of cancer patients, and it has later been documented that DNA methylations are chemically and biologically stable, also on cell-free cancer DNA in the blood (31-35). The DNA molecule itself is more stable to work with than RNA or protein, and methylation patterns are easier to detect than mutations as they are binary signals and can be amplified by methylation-specific PCR-based techniques (36). Besides, DNA methylation analysis can be focused on the $\mathrm{CpG}$ sites, which mean there is no need to scan the whole gene as for mutations.

To be able to give information that is useful in a diagnostic or prognostic setting, a molecular marker should change behavior in a detectable way which can be correlated with important pathogenic processes and steps of disease development. Patterns of DNA methylation has potential both as prognostic and diagnostic markers, as changes in DNA methylation has been correlated to early carcinogenesis, even prior to tumor formation, as well as to the process of metastasis and to sensitivity to treatment (37-40).

\section{Methods for detection of methylation}

DNA methylation can be detected as a binary signal, either methylated or not methylated. Several technologies have been developed to identify the methylation status of CpGs. The best known and most widespread methods involve bisulfite conversion of cytosine to uracil. Methylated cytosines won't be converted and several methods can be used to identify the non-converted CpGs. Sequencing of the bisulfite converted DNA is generally considered the golden standard and is widely used. However, it is quite expensive. Another popular method to detect bisulfite converted cytosines is methylation-specific PCR (MSP). In this quick assay, DNA is amplified from primers specific for either the converted or not-converted sequence (41). For easier detection of low-abundant methylations in samples with excess of unmethylated DNA, a methylation-specific qPCR (qMSP) can be run.

Alternative methods to detection of methylation status often involve methylation-specific restriction sites. In the simplest version, DNA is cut with a restriction enzyme for which its activity is dependent on methylation status of the restriction site. A subsequent PCR will only amplify uncut DNA, thereby revealing whether it was methylated or not. This concept is also applied in the methylation sensitive amplified polymorphism method, where differences in DNA fragments after digestion with methylation-specific restriction enzymes can be used to compare methylation differences in different sample types (42). It is an advantage of the latter method, that prior, detailed knowledge of the genomic sequence is not required. In case the genomic sequence is known, and methylation status of specific targets is of interest, Methylation-specific, Multiplex ligation-dependent probe amplification can be used (43). This method recognizes the area of interest with a probe prior to digestion with methylation sensitive restriction enzymes, and proliferation of the probe thereby depends on methylation status of the area attached to the probe.

A newer, quantitative, high-throughput methodology for studies of methylation sites is the one applied by the Sequenom MassArray technology. DNA methylation is analyzed by mass spectrometry after base-specific cleavage. After bisulfite modification, RNA is transcribed from the genomic sequence of interest, and cleaved base-specifically. Methylation and bisulfite conversion changes the atomic mass and the extent of methylation can measured by mass spectrometry (44).

To identify methylation patterns, which can be used as biomarkers, it is necessary with more genome-wide approaches. Whole genome bisulfite sequencing is a possibility, but rather expensive and ineffective (45). Illumina has gained popularity with their Infinium HumanMethylation BeadChip methodology. The chips contain beads with attached probes which recognize either methylated or un-methylated methylation sites, after bisulfite conversion. The newest version, the Infinium Methylation EPIC array, gives single-base methylation information for over $850.000 \mathrm{CpGs}$ throughout the genome. A vast amount of the CpGs targeted by the EPIC 
array are in regulatory areas like promoters and enhancers, relevant for human cancer biology, and the array has a high potential for identification of new cancer biomarkers.

\section{DNA hypermethylation in OC}

DNA methylation has been shown to be a major player in OC and several tumor suppressor genes have been shown to be hypermethylated. Methylation of $B R C A 1$ promoters has gained a lot of attention, since $B R C A 1$ mutations are known to be involved in inherited OC (46,47). BRCAl promoter hypermethylation can be found in $15-30 \%$ of ovarian carcinomas $(46,48,49)$. In a study on 50 patients from $2004,68 \%$ of the patients were methylated in either BRCAl or the RASSFIA gene (35). The study found that all patients were hypermethylated in one or more tumor suppressor genes, and hypermethylation was found in all histological types, grades, and stages of OCs examined, illustrating that hypermethylation is a widespread phenomenon in OC. RASSF1A promoter hypermethylation in OC has been observed in other studies, and it might be one of the most frequently methylated genes in OC, one study even observed it in as much as $49 \%$ of 52 carcinomas (50). However, other studies only found RASSFIA promotor methylation in 10-12\% of ovarian tumors but in $40 \%$ of ovarian tumor cell lines $(51,52)$. Two other tumor suppressor genes are frequently methylated in their promotors in $\mathrm{OC}$, as shown by several independent studies. One of these is $O P C M L$, which in one study was found methylated in as much as $83 \%$ of ovarian tumors (53-55). The other is the gene Pl6INK4a. A meta-study from 2016, including 612 OC patients and 289 controls from 12 studies, confirmed that PI6INK4a promoter hypermethylation is found regularly in OC while rarely found in controls (21).

Studies investigating the stem cell nature of cancers, have shown that stem cell PolyComb group targets are up to 12 -fold more likely to have cancer-specific promoter hypermethylation than non-targets (56). The PolyComb group targets are transcription factors involved in differentiation, and their transcription is normally repressed reversibly in embryonic stem cells. As part of carcinogenesis, repression of these genes can be made irreversible by promoter methylation, and the result is a cell that will continue to renew itself, leading to tumorigenesis. Hypermethylation at stem cell PolyComb Group Target genes in OC and other women's cancers was confirmed in a large screening of 1475 samples in 2012 (40).

A study from 2015 showed that epigenetic suppression of ten genes was involved in the development of non-serous OC, including OPCML and the promotor of microRNA (miRNA) $m i R-34 b$ (57). The cancer suppressive nature of some miRNAs is gaining more focus these years, and an increasing body of evidence suggests a cancer suppressive role of the miR-34 family, which is part of the p53 cancer suppressive network. A study from 2016 states a correlation between type II OC and hypermethylation of $m i R-34 a$ (58). The miRNA miR-30d has also been shown to counteract OC. Hypermethylation of the miR-30d promoter was seen for TGF- $\beta 1$ induced epithelial-mesenchymal transition of OC cells (59). The most recent research on hypermethylation of gene promotors suggests that genes KLF11, ARHI, GBGTI and PDLIM2 are hypermethylated in OC (60-63). All 4 genes were hypermethylated while their expression was reduced in either OC cell-lines, tissue from OC patients or both. A few other genes have been reported to have very high promoter methylation $(>50 \%)$ in OC in individual studies. This goes for $h M S H 2$ and HSulf- 1 but the reported data needs to be followed up with validation studies $(64,65)$.

\section{DNA hypomethylation in OC}

Hypomethylation in OC is less studied than hypermethylation but has gained more focus in recent years. Hypomethylation can cause cancer through different mechanisms. Widespread loss of methylation results in a general DNA instability, which will typically lead to increased mutation frequency and a risk of cancer. However, most studies focus on hypomethylation of specific CpGs. Reduced methylation in regulatory areas of oncogenes affects transcription, often increasing it. A study from 2009 suggests that hypomethylation is the most common methylation change in OC. Around 27,000 CpGs were screened in $113 \mathrm{OC}$ cases and 148 healthy controls, and a total of 2,714 cancer related CpGs were identified. $56 \%$ of these were hypomethylated, but amongst the $50 \mathrm{CpGs}$ with the highest correlation to cancer as much as $87 \%$ were hypomethylated (34). A later and larger study, including 1,475 samples, suggests that cancer specific hypomethylation in women's cancers occurs preferentially at a specific set of CpGs which are normally heavily methylated in embryonic stem cells (called MESC) (40). Hypomethylation of MESCs is associated with tissue invasion and metastasis.

Two studies from 2016 show examples of how hypomethylation of promoters is involved in OC. One study shows that the gene for the proto-oncogenic, cell-cycle regulator $\mathrm{Cdk} 2$ is both hypomethylated and overexpressed in OC tumors (66). The other shows that the gene for the oncogenic cancer-testis antigen PRAME very often has reduced promoter methylation, which correlates with increased expression (67).

\section{Potential of DNA methylation in OC diagnostics}

For a biomarker to be useful in identifying cancer patients in early stage of disease, it should be capable of differentiation between patients with benign tumors and early stage cancers, preferable without invasive, surgical procedures. This could be done by detection in body fluids, e.g., blood. The earlier the marker can be detected, optimally a long time before clinical presentation, the better the chance of improving patient survival. Changes in methylation have in several cases been shown to take place very early, before actual tumor growth or cancerous cells can be found in a clinical setting. One example of this is hypermethylation of PolyComb Group Target genes, which was detected up to 3 years before cancer cells appeared in a screening trial for cervix cancer (40).

To increase sensitivity and specificity, a panel of CpG-sites covering several genes can potentially be used. This approach was tried in a paper from 2009, which achieved a sensitivity of $85 \%$ and a specificity of $61 \%$ differentiating between OC patients and healthy controls. They measured the methylation status of 5 gene promoters, including the $B R C A 1$ promoter, on circulating DNA in the plasma (68). This result was followed-up by a study which gained a sensitivity of $90 \%$ and a specificity of $86,7 \%$ using only 3 genes, including RASSF1A (69). 
RASSF1A was also included in another promising gene-panel, which together with $O P C M L$ included a total of 7 genes. This panel was also applied on cell-free serum DNA, and tested on 202 OC patients, 53 patients with benign tumors and 62 healthy controls. The panel achieved a sensitivity of $85,3 \%$ and a specificity of $90,5 \%$ (70).

The tumor suppressor genes RASSF1A and OPCML are seen in several new papers on OC diagnostics. In 2015, Xing et al showed that they could achieve a specificity of impressing $100 \%$ with a sensitivity of $85,7 \%$ looking at methylation of RASSF1A, OPCML and HOXA9 (71). None of the 3 genes alone gave as impressive a result. However, the setup only included tissue from 35 patients and 11 controls. A larger study, including both serum and tissue for $114 \mathrm{OC}$ patients, used methylation of $O P C M L$ together with tumor suppressor genes RUNX3 and TFPI2 (72). They demonstrated that their methylation analysis could identify early OC with a higher sensitivity and specificity than CA125 serum levels. The same was suggested for OPCML alone in a study from 2017, including free circulating DNA from 71 OC patients, 80 healthy controls and 43 patients with benign ovarian tumors (73).

Data from 2014 suggests an association between OC and methylation of leukocyte DNA (74). The authors argue that since tumorigenesis is not an isolated phenomenon but result from alterations in processes also affecting neighboring tissue and the immune system, leukocyte cells may be informative regarding cancer. Some groups have explored this and applied screening of patient leukocyte DNA, using Illumina Infinium arrays which covers $450.000 \mathrm{CpG}$ sites. A study from 2014 screened blood DNA from 242 OC cases and 181 age-matched healthy controls. By adjusting for leukocyte distribution, overcoming confounding caused by immune-responses against the cancer, they identified a $\mathrm{CpG}$ island in the promoter of $B N C 2$ as being top-associated with OC (75). Another group used a similar screening method, combined with the Illumina Custom VeraCode methylation assay in a new study from 2017 (76). Their analysis pointed at $6 \mathrm{CpG}$ sites associated with $\mathrm{OC}$, primarily located in immune system process genes.

\section{Potential of DNA methylation in OC prognostics}

A follow-up study on the work done on hypermethylation of stem cell PolyComb Group Target genes in OC (40) identified HOXA11 methylation as a potential prognostic marker in OC patients (77). Amongst 71 loci, investigated in $22 \mathrm{OCs}$ and 18 controls, HOXA10 and HOXA11 were most accurately discriminating between $\mathrm{OC}$ and non-neoplastic tissue, and HOXA11 methylation was associated with a bad prognosis for the patient. HOXA9 methylation is also highly related to $\mathrm{OC}$ and found in all stages of the disease $(78,79)$. However, HOXA9 methylation tend to be lower in high grade OC compared to low grade and may therefore be used as an indicator of disease grade (57).

Promotor hypermethylation with reduced gene expression is prognostic of a shorter progression free survival (PFS) in several newer studies. RUNX3 and IQGAP2 are a couple of the genes that can be mentioned $(80,81)$. Reduced expression of $m i R-34 a$, correlating with promoter hypermethylation, predicts reduced overall survival (OS) and PFS in OC patients (58). However, $m i R-34 a$ expression also correlates negatively with Paclitaxel sensitivity in the NCI60 cell line panel (82). This may reflect a tendency observed for the upstream protein p53. Even though p53 is a well described cancer suppressor, overexpression of the protein has been correlated to chemotherapy resistance $(83,84)$.

Hypomethylation might also be of prognostic value. MESC hypomethylation progresses as the cancer develops from a primary cancer and start metastasizing (40). It may therefore hold information of the OC stage and the chance of survival. PRAME hypomethylation and expression is related to increased survival in high grade serous carcinoma (67). Several new studies have suggested that hypomethytlation and increased expression of potential proto-oncogenes predict more aggressive and metastatic $\mathrm{OC}$ with a potentially lower survival. This has been seen for GABRP, SLC6A12, MGAT3, CT45, CA9, MUC13 and AGR2 (85-91).

Metastasis and methylation might be tightly connected as highlighted by a study from 2014. A key player in metastasis is the transforming growth factor TGF- $\beta$. TGF- $\beta$ stimulation of OC cell lines extensively change DNA methylation, especially in the promoters of genes involved in the epithelial-mesenchymal transition and cancer progression (92).

\section{DNA methylation profiles as markers for OC screening}

As OC patients experience no or very unspecific symptoms, a screening program would be a major, lifesaving advance. A recent study investigated possible markers for a screening setting, but no optimal marker was identified. However, screening for OC is theoretically possible $(14,93)$.

The ideal marker for screening needs to be accessible without surgical procedures and occur in early states of a disease. Thus, the prerequisite for using aberrant DNA methylation in screening seems to be there. Recent data suggest that the most OC tumors originate from precursor lesions in the fimbrial part of the fallopian tube rather than from ovarian tissue (94-101). Fluid and oocytes from tubes and ovaries pass through cervix and the tubes and cervix are parts of the same organ. It can therefore be speculated that methylated DNA, indicative of changes in pre-malignant or malignant tissue of tubal origin, can be detected in the cervical canal. If it was possible to identify OC using a standard cytological test from the cervix, a screening program for OC could be included in the existing screening program for cervical cancer. Methylation changes in fimbrial cells, which can identify ovarian carcinomas, have already been described (102). Likewise, it has also been possible to identify an association between methylation of PolyComb group target genes HOXA9 and HOXA11 in normal endometrium and the presence of OC (79). Even more promising, data show that methylation patterns specific for cervix and endometrial cancers can be identified on DNA from patient vaginal fluid (103).

\section{DNA methylation and the prediction of chemo-resistance}

The standard first line of OC treatment is platinum-based chemotherapy, and approximately $80 \%$ of the patients respond to first line treatment. However, most patients develop resistance to treatment over time. Predictive biomarkers, that can identify patients applicable for specific treatments, can be used to direct the treatment and avoid ineffective treatment-strategies. 
Recently it was shown that the platinum-based therapy itself can induce aberrant methylation at specific methylation sites in OC patients, and that this methylation is associated with patient survival (39). As the methylation can be detected in a blood test at the time of relapse, it could possibly function as both a predictive and prognostic marker and give information about response to platinum-based medication and survival. Supporting the importance of methylation in platinum resistance, it has been shown that the methylation inhibitor SGI-110 can re-sensitize chemo-resistant OC stem-like cells, by resetting the cells to a more differentiated phenotype (104).

Several studies from recent years have supported an association between hypermethylation and chemo-resistance. A study from 2017 describe how DNA methylation is involved in reducing expression of the $\mathrm{T}$-cell activating ligands 4-1BBL/CD157 and OX-40L/CD252 in chemo-resistant OC cells (105). Apparently, this mechanism of immune suppression helps the cancer evade immune responses stimulated by chemotherapy. An integrative analysis has discovered a network of interacting genes, for whom methylation associates with resistance towards chemotherapy (106). PTEN seems to be a key regulator in the network. Other examples worth mentioning are $R G S 2$, which is hypermethylated in chemo-resistant cells, and FAM83A and MYO18B methylation which has been seen in non-responders $(107,108)$.

A study from 2017 also suggests that hypomethylation can be induced by cisplatin treatment in resistant OC patients, however loss of methylation was primarily observed in intergenic regions (109). Other recent studies have suggested a correlation between hypomethylation of developmental genes and platinum resistance in OC patients. Amongst these, MSXI and TMEM 88 can be mentioned $(110,111)$. Especially regulation of the epithelial-to-mesenchymal transition by changes in methylation seems to be an important part of platinum resistance. The non-coding RNA HOTAIR induces the epithelial-to-mesenchymal transition together with Platinum resistance and is regulated by methylation (112). Another example of a similar dynamic was seen for an OC-cell model, where TET expression was increased in platinum resistant cells. TET stimulates the epithelial-to-mesenchymal transition by blocking promotor methylation of Vimentin, a mediator of chemo-resistance which has been described as a potential therapeutic marker (113).

\section{Discussion}

The advantages of using DNA methylation as a cancer marker are evident. However, DNA methylations as cancer biomarkers are still a relatively new area. Only few methylation markers are used in clinical decision making. One example is methylation of DNA repair genes which is used to differentiate between hereditary and non-hereditary colorectal cancer.

A most exciting potential for DNA methylation markers are as early markers which can be detected pro-surgery. However, there is a challenge to interpretations of markers from body-fluids compared to tumor-samples. It can be difficult to differentiate between methylation changes directly related to the $\mathrm{OC}$ and methylation changes related to other tumors or to the general immunological response to the cancer. Therefore, studies investigating corresponding biological material are needed.
It is clear at this point that DNA methylation is involved in the progression of OC. However, despite an increasing number of reports on methylation changes in OC patients, most often the reported changes are not validated by independent studies. Several interesting methylation changes have been observed in several OC studies. Amongst them are those in the promotors of the tumor suppressor genes BRCA1, RASSF1A, OPCML and HOXA9 and the proto-oncogene PRAME. Nonetheless, methylation patterns which can be found in a high proportion of OCs are needed. At this stage, no DNA methylation site identified has the specificity and sensitivity to identify $\mathrm{OC}$ alone. One reason for this is that most of the previous studies have focused on only one or a few candidate genes. To succeed in the discovery of satisfying OC markers, more genome wide approaches and screening methods must be applied. Also, future discovery studies should cover not only benign and malign samples, but also different subgroups of stages of carcinogenesis as well as both chemo responsive and resistant patients. It is of great importance that we get a better understanding of the initiation and progression of $\mathrm{OC}$, and the methylation landscape guiding, or resulting from, these processes. As the main challenge is that symptoms of $\mathrm{OC}$ are unspecific and diffuse, it is of high priority to understand early methylation changes and how to detect them without invasive measures. We need to determine the methylation signature of OC in detail before we can identify markers which can improve both diagnostics and treatment of OC patients.

The latest $\mathrm{OC}$ research has indicated that screening and early diagnosis is attainable. Yet, at this point, $\mathrm{OC}$ is still the leading cause of death from gynecological malignancies. A first step could be to improve treatment and survival by precision medicine guided by biomarkers, moving towards making OC a chronic disease with high life quality. However, the long-term goal must be to improve early diagnosis to an extend where the cancer is discovered and treated before it spreads, with the result of largely improved survival. Genome-wide studies resulting in a better understanding of the disease etiology will hopefully bring us to the point where OC is either a chronic disease a disease that can be cured.

\section{Acknowledgements}

Not applicable.

\section{Funding}

This work is supported by Mermaid III.

\section{Availability of data and materials}

All data generated or analyzed during this study are included in this published article. Papers reviewed are accessible through Pubmed.

\section{Authors' contributions}

JLH made substantial contributions to design and acquisition of data, was involved in drafting the manuscript, gave final approval of the version to be published. EVH and CKH also made substantial contributions to conception and design and 
revised the manuscript critically for important intellectual content. All authors approved the final version of the manuscript.

\section{Ethics approval and consent to participate}

Not applicable.

\section{Patient consent for publication}

Not applicable.

\section{Competing interests}

The authors declare that they have no competing interests.

\section{References}

1. DGCG (2016-2017) DGCD årsreport: http://dgcg.dk/images/ Grupper/Databasegruppen/rsrapport_DGCD_2016-17_endelig anonymiseret.pdf.

2. Siegel RL, Miller KD and Jemal A: Cancer statistics, 2016. CA Cancer J Clin 66: 7-30, 2016.

3. Torre LA, Bray F, Siegel RL, Ferlay J, Lortet-Tieulent J and Jemal A: Global cancer statistics, 2012. CA Cancer J Clin 65: 87-108, 2015.

4. Prat J; Figo Committee on Gynecologic Oncology: Staging classification for cancer of the ovary, fallopian tube, and peritoneum. Int J Gynaecol Obstet 124: 1-5, 2014.

5. Hamilton W, Peters TJ, Bankhead C and Sharp D: Risk of ovarian cancer in women with symptoms in primary care: Population based case-control study. BMJ 339: b2998, 2009.

6. DGCG Ovariecancer guidelines: http://www.dgcg.dk/index.php/ guidelines/ovariecancer-guidelines Accessed Jul 1, 2016.

7. Jacobs I, Oram D, Fairbanks J, Turner J, Frost C and Grudzinskas JG: A risk of malignancy index incorporating CA 125, ultrasound and menopausal status for the accurate preoperative diagnosis of ovarian cancer. Br J Obstet Gynaecol 97: 922-929, 1990.

8. Nossov V, Amneus M, Su F, Lang J, Janco JM, Reddy ST and Farias-Eisner R: The early detection of ovarian cancer: From traditional methods to proteomics. Can we really do better than serum CA-125? Am J Obstet Gynecol 199: 215-223, 2008.

9. Sundar S, Neal RD and Kehoe S: Diagnosis of ovarian cancer. BMJ 351: h4443, 2015.

10. Moss EL, Hollingworth J and Reynolds TM: The role of CA125 in clinical practice. J Clin Pathol 58: 308-312, 2005.

11. Meden H and Fattahi-Meibodi A: CA 125 in benign gynecological conditions. Int J Biol Markers 13: 231-237, 1998.

12. Buamah P: Benign conditions associated with raised serum CA-125 concentration. J Surg Oncol 75: 264-265, 2000.

13. Rai N, Nevin J, Downey G, Abedin P, Balogun M, Kehoe S and Sundar S: Outcomes following implementation of symptom triggered diagnostic testing for ovarian cancer. Eur J Obstet Gynecol Reprod Biol 187: 64-69, 2015.

14. Jacobs IJ, Menon U, Ryan A, Gentry-Maharaj A, Burnell M, Kalsi JK, Amso NN, Apostolidou S, Benjamin E, Cruickshank D, et al: Ovarian cancer screening and mortality in the UK collaborative trial of ovarian cancer screening (UKCTOCS): A randomised controlled trial. Lancet 387: 945-956, 2016.

15. Martin LP and Schilder RJ: Management of recurrent ovarian carcinoma: Current status and future directions. Semin Oncol 36 : $112-125,2009$

16. Wolffe AP and Matzke MA: Epigenetics: Regulation through repression. Science 286: 481-486, 1999.

17. Borgel J, Guibert S, Li Y, Chiba H, Schübeler D, Sasaki H, Forné T and Weber M: Targets and dynamics of promoter DNA methylation during early mouse development. Nat Genet 42: 1093-1100, 2010.

18. Mohandas T, Sparkes RS and Shapiro LJ: Reactivation of an inactive human X chromosome: Evidence for X inactivation by DNA methylation. Science 211: 393-396, 1981.

19. Herman JG, Latif F, Weng Y, Lerman MI,Zbar B, Liu S, Samid D, Duan DS, Gnarra JR, Linehan WM, et al: Silencing of the VHL tumor-suppressor gene by DNA methylation in renal carcinoma. Proc Natl Acad Sci USA 91: 9700-9704, 1994.
20. Jones PA and Baylin SB: The fundamental role of epigenetic events in cancer. Nat Rev Genet 3: 415-428, 2002.

21. Xiao X, Cai F, Niu X, Shi H and Zhong Y: Association between P16INK4a promoter methylation and ovarian cancer: A meta-analysis of 12 published studies. PLoS One 11: e0163257, 2016.

22. Brait M, Ford JG, Papaiahgari S, Garza MA, Lee JI, Loyo M, Maldonado L, Begum S, McCaffrey L, Howerton M, et al: Association between lifestyle factors and $\mathrm{CpG}$ island methylation in a cancer-free population. Cancer Epidemiol Biomarkers Prev 18: 2984-2991, 2009.

23. Issa JP, Ahuja N, Toyota M, Bronner MP and Brentnall TA: Accelerated age-related $\mathrm{CpG}$ island methylation in ulcerative colitis. Cancer Res 61: 3573-3577, 2001.

24. Patra SK, Patra A, Zhao H and Dahiya R: DNA methyltransferase and demethylase in human prostate cancer. Mol Carcinog 33: 163-171, 2002.

25. Saito Y, Kanai Y, Nakagawa T, Sakamoto M, Saito H, Ishii H and Hirohashi S: Increased protein expression of DNA methyltransferase (DNMT) 1 is significantly correlated with the malignant potential and poor prognosis of human hepatocellular carcinomas. Int J Cancer 105: 527-532, 2003.

26. Feinberg AP and Vogelstein B: Hypomethylation distinguishes genes of some human cancers from their normal counterparts. Nature 301: 89-92, 1983.

27. Ehrlich M: DNA methylation in cancer: Too much, but also too little. Oncogene 21: 5400-5413, 2002.

28. Xiong Y, Dowdy SC, Xue A, Shujuan J, Eberhardt NL, Podratz KC and Jiang SW: Opposite alterations of DNA methyltransferase gene expression in endometrioid and serous endometrial cancers. Gynecol Oncol 96: 601-609, 2005.

29. Eden A, Gaudet F, Waghmare A and Jaenisch R: Chromosomal instability and tumors promoted by DNA hypomethylation. Science 300: 455, 2003.

30. Gaudet F, Hodgson JG, Eden A, Jackson-Grusby L, Dausman J, Gray JW, Leonhardt H and Jaenisch R: Induction of tumors in mice by genomic hypomethylation. Science 300: 489-492, 2003.

31. Esteller M, Sanchez-Cespedes M, Rosell R, Sidransky D, Baylin SB and Herman JG: Detection of aberrant promoter hypermethylation of tumor suppressor genes in serum DNA from non-small cell lung cancer patients. Cancer Res 59: 67-70, 1999.

32. Sanchez-Cespedes M, Esteller M, Wu L, Nawroz-Danish H, Yoo GH, Koch WM, Jen J, Herman JG and Sidransky D: Gene promoter hypermethylation in tumors and serum of head and neck cancer patients. Cancer Res 60: 892-895, 2000.

33. Talens RP, Boomsma DI, Tobi EW, Kremer D, Jukema JW, Willemsen G, Putter H, Slagboom PE and Heijmans BT: Variation, patterns, and temporal stability of DNA methylation: Considerations for epigenetic epidemiology. FASEB J 24: 3135-3144, 2010.

34. Teschendorff AE, Menon U, Gentry-Maharaj A, Ramus SJ, Gayther SA, Apostolidou S, Jones A, Lechner M, Beck S, Jacobs IJ and Widschwendter M: An epigenetic signature in peripheral blood predicts active ovarian cancer. PLoS One 4: e8274, 2009.

35. Ibanez de Caceres I, Battagli C, Esteller M, Herman JG, Dulaimi E, Edelson MI, Bergman C, Ehya H, Eisenberg BL and Cairns P: Tumor cell-specific BRCA1 and RASSF1A hypermethylation in serum, plasma, and peritoneal fluid from ovarian cancer patients. Cancer Res 64: 6476-6481, 2004.

36. Barton CA, Hacker NF, Clark SJ and O'Brien PM: DNA methylation changes in ovarian cancer: Implications for early diagnosis, prognosis and treatment. Gynecol Oncol 109: 129-139, 2008.

37. Teschendorff AE, Jones A, Fiegl H, Sargent A, Zhuang JJ, Kitchener HC and Widschwendter M: Epigenetic variability in cells of normal cytology is associated with the risk of future morphological transformation. Genome Med 4: 24, 2012.

38. Teschendorff AE and Widschwendter $\mathrm{M}$ : Differential variability improves the identification of cancer risk markers in DNA methylation studies profiling precursor cancer lesions. Bioinformatics 28: 1487-1494, 2012.

39. Flanagan JM, Wilson A, Koo C, Masrour N, Gallon J, Loomis E, Flower K, Wilhelm-Benartzi C, Hergovich A, Cunnea P, et al: Platinum-based chemotherapy induces methylation changes in blood DNA associated with overall survival in patients with ovarian cancer. Clin Cancer Res 23: 2213-2222, 2017.

40. Zhuang J, Jones A, Lee SH, Ng E, Fiegl H, Zikan M, Cibula D, Sargent A, Salvesen HB, Jacobs IJ, et al: The dynamics and prognostic potential of DNA methylation changes at stem cell gene loci in women's cancer. PLoS Genet 8: e1002517, 2012. 
41. Herman JG, Graff JR, Myohanen S, Nelkin BD and Baylin SB: Methylation-specific PCR: A novel PCR assay for methylation status of CpG islands. Proc Natl Acad Sci USA 93: 9821-9826, 1996.

42. Reyna-López GE, Simpson J and Ruiz-Herrera J: Differences in DNA methylation patterns are detectable during the dimorphic transition of fungi by amplification of restriction polymorphisms. Mol Gen Genet 253: 703-710, 1997.

43. Moelans CB, Atanesyan L, Savola SP and van Diest PJ: Methylation-specific multiplex ligation-dependent probe amplification (MS-MLPA). Methods Mol Biol 1708: 537-549, 2018.

44. Ehrich M, Nelson MR, Stanssens P, Zabeau M, Liloglou T, Xinarianos G, Cantor CR, Field JK and van den Boom D: Quantitative high-throughput analysis of DNA methylation patterns by base-specific cleavage and mass spectrometry. Proc Natl Acad Sci USA 102: 15785-15790, 2005.

45. Ziller MJ, Gu H, Müller F, Donaghey J, Tsai LT, Kohlbacher O, De Jager PL, Rosen ED, Bennett DA, Bernstein BE, et al: Charting a dynamic DNA methylation landscape of the human genome. Nature 500: 477-481, 2013.

46. Baldwin RL, Nemeth E, Tran H, Shvartsman H, Cass I, Narod S and Karlan BY: BRCA1 promoter region hypermethylation in ovarian carcinoma: A population-based study. Cancer Res 60 : $5329-5333,2000$

47. Hilton JL, Geisler JP, Rathe JA, Hattermann-Zogg MA, DeYoung B and Buller RE: Inactivation of BRCA1 and BRCA2 in ovarian cancer. J Natl Cancer Inst 94: 1396-1406, 2002.

48. Strathdee G, Appleton K, Illand M, Millan DW, Sargent J, Paul J and Brown R: Primary ovarian carcinomas display multiple methylator phenotypes involving known tumor suppressor genes Am J Pathol 158: 1121-1127, 2001.

49. Wang C, Horiuchi A, Imai T, Ohira S, Itoh K, Nikaido T, Katsuyama Y and Konishi I: Expression of BRCA1 protein in benign, borderline, and malignant epithelial ovarian neoplasms and its relationship to methylation and allelic loss of the BRCA1 gene. J Pathol 202: 215-223, 2004.

50. Wu Q, Lothe RA, Ahlquist T, Silins I, Tropé CG, Micci F, Nesland JM, Suo Z and Lind GE: DNA methylation profiling of ovarian carcinomas and their in vitro models identifies HOXA9, HOXB5, SCGB3A1, and CRABP1 as novel targets. Mol Cancer 6: 45, 2007.

51. Agathanggelou A, Honorio S, Macartney DP, Martinez A, Dallol A, Rader J, Fullwood P, Chauhan A, Walker R, Shaw JA, et al: Methylation associated inactivation of RASSF1A from region 3 p21.3 in lung, breast and ovarian tumours. Oncogene 20: 1509-1518, 2001.

52. Ozdemir F, Altinisik J, Karateke A, Coksuer H and Buyru N Methylation of tumor suppressor genes in ovarian cancer. Exp Ther Med 4: 1092-1096, 2012.

53. Teodoridis JM, Hall J, Marsh S, Kannall HD, Smyth C, Curto J, Siddiqui N, Gabra H, McLeod HL, Strathdee G and Brown R: $\mathrm{CpG}$ island methylation of DNA damage response genes in advanced ovarian cancer. Cancer Res 65: 8961-8967, 2005.

54. Czekierdowski A, Czekierdowska S, Szymanski M, Wielgos M, Kaminski P and Kotarski J: Opioid-binding protein/cell adhesion molecule-like (OPCML) gene and promoter methylation status in women with ovarian cancer. Neuro Endocrinol Lett 27: 609-613, 2006.

55. Sellar GC, Watt KP, Rabiasz GJ, Stronach EA, Li L, Miller EP, Massie CE, Miller J, Contreras-Moreira B, Scott D, et al: OPCML at 11q25 is epigenetically inactivated and has tumor-suppressor function in epithelial ovarian cancer. Nat Genet 34: 337-343, 2003.

56. Widschwendter M, Fiegl H, Egle D, Mueller-Holzner E, Spizzo G, Marth C, Weisenberger DJ, Campan M, Young J, Jacobs I and Laird PW: Epigenetic stem cell signature in cancer. Nat Genet 39: 157-158, 2007.

57. Niskakoski A, Kaur S, Staff S, Renkonen-Sinisalo L, Lassus H, Järvinen HJ, Mecklin JP, Bützow R and Peltomäki P: Epigenetic analysis of sporadic and Lynch-associated ovarian cancers reveals histology-specific patterns of DNA methylation. Epigenetics 9: $1577-1587,2014$.

58. Schmid G, Notaro S, Reimer D, Abdel-Azim S, Duggan-Peer M, Holly J, Fiegl H, Rössler J, Wiedemair A, Concin N, et al: Expression and promotor hypermethylation of miR-34a in the various histological subtypes of ovarian cancer. BMC Cancer 16: $102,2016$.

59. Ye Z, Li J, Han X, Hou H, Chen H, Zheng X, Lu J, Wang L, Chen W, Li X and Zhao L: TET3 inhibits TGF- $\beta 1$-induced epithelial-mesenchymal transition by demethylating miR-30d precursor gene in ovarian cancer cells. J Exp Clin Cancer Res 35: 72,2016
60. Wang G, Li X, Tian W, Wang Y, Wu D, Sun Z and Zhao E: Promoter DNA methylation is associated with KLF11 expression in epithelial ovarian cancer. Genes Chromosomes Cancer 54: 453-462, 2015

61. Zhao L, Yu C, Zhou S, Lau WB, Lau B, Luo Z, Lin Q, Yang H, Xuan Y, Yi T, et al: Epigenetic repression of PDZ-LIM domain-containing protein 2 promotes ovarian cancer via NOS2-derived nitric oxide signaling. Oncotarget 7: 1408-1420, 2016.

62. Fu Y, Chen J, Pang B, Li C, Zhao J and Shen K: EZH2-induced $\mathrm{H} 3 \mathrm{~K} 27 \mathrm{me} 3$ is associated with epigenetic repression of the ARHI tumor-suppressor gene in ovarian cancer. Cell Biochem Biophys 71: 105-112, 2015.

63. Jacob F, Hitchins MP, Fedier A, Brennan K, Nixdorf S, Hacker NF, Ward R and Heinzelmann-Schwarz VA: Expression of GBGT1 is epigenetically regulated by DNA methylation in ovarian cancer cells. BMC Mol Biol 15: 24, 2014.

64. Staub J, Chien J, Pan Y, Qian X, Narita K, Aletti G, Scheerer M, Roberts LR, Molina J and Shridhar V: Epigenetic silencing of HSulf-1 in ovarian cancer:implications in chemoresistance. Oncogene 26: 4969-4978, 2007.

65. Zhang H, Zhang S, Cui J, Zhang A, Shen L and Yu H: Expression and promoter methylation status of mismatch repair gene hMLH1 and hMSH2 in epithelial ovarian cancer. Aust N Z J Obstet Gynaecol 48: 505-509, 2008.

66. Kanwal A, Kaur M, Singh A, Gupta S and Sachan M: Hypo/unmethylated promoter status of Cdk2 gene correlates with its over-expression in ovarian cancer in north Indian population. Cell Mol Biol (Noisy-le-grand) 62: 67-72, 2016.

67. Zhang W, Barger CJ, Eng KH, Klinkebiel D, Link PA, Omilian A, Bshara W, Odunsi K and Karpf AR: PRAME expression and promoter hypomethylation in epithelial ovarian cancer. Oncotarget 7: 45352-45369, 2016.

68. Melnikov A, Scholtens D, Godwin A and Levenson V: Differential methylation profile of ovarian cancer in tissues and plasma. J Mol Diagn 11: 60-65, 2009.

69. Liggett TE, Melnikov A, Yi Q, Replogle C, Hu W, Rotmensch J, Kamat A, Sood AK and Levenson V: Distinctive DNA methylation patterns of cell-free plasma DNA in women with malignant ovarian tumors. Gynecol Oncol 120: 113-120, 2011.

70. Zhang Q, Hu G, Yang Q, Dong R, Xie X, Ma D, Shen K and Kong B: A multiplex methylation-specific PCR assay for the detection of early-stage ovarian cancer using cell-free serum DNA. Gynecol Oncol 130: 132-139, 2013.

71. Xing BL, Li T, Tang ZH, Jiao L, Ge SM, Qiang X and OuYang J: Cumulative methylation alternations of gene promoters and protein markers for diagnosis of epithelial ovarian cancer. Genet Mol Res 14: 4532-4540, 2015.

72. Wang B, Yu L, Yang GZ, Luo X and Huang L: Application of multiplex nested methylated specific PCR in early diagnosis of epithelial ovarian cancer. Asian Pac J Cancer Prev 16: 3003-3007, 2015.

73. Wang B, Yu L, Luo X, Huang L, Li OS, Shao XS, Liu Y, Fan Y and Yang GZ: Detection of OPCML methylation, a possible epigenetic marker, from free serum circulating DNA to improve the diagnosis of early-stage ovarian epithelial cancer. Oncol Lett 14: 217-223, 2017.

74. Koestler DC, Chalise P, Cicek MS, Cunningham JM, Armasu S, Larson MC, Chien J, Block M, Kalli KR, Sellers TA, et al: Integrative genomic analysis identifies epigenetic marks that mediate genetic risk for epithelial ovarian cancer. BMC Med Genomics 7: 8, 2014.

75. Winham SJ, Armasu SM, Cicek MS, Larson MC, Cunningham JM, Kalli KR, Fridley BL and Goode EL: Genome-wide investigation of regional blood-based DNA methylation adjusted for complete blood counts implicates BNC2 in ovarian cancer. Genet Epidemiol 38: 457-466, 2014.

76. Li L, Zheng H, Huang Y, Huang C, Zhang S, Tian J, Li P, Sood AK, Zhang W and Chen K: DNA methylation signatures and coagulation factors in the peripheral blood leucocytes of epithelial ovarian cancer. Carcinogenesis 38: 797-805, 2017.

77. Fiegl H, Windbichler G, Mueller-Holzner E, Goebel G, Lechner M, Jacobs IJ and Widschwendter M: HOXA11 DNA methylation-a novel prognostic biomarker in ovarian cancer. Int J Cancer 123: 725-729, 2008

78. Montavon C, Gloss BS, Warton K, Barton CA, Statham AL, Scurry JP, Tabor B, Nguyen TV, Qu W, Samimi G, et al: Prognostic and diagnostic significance of DNA methylation patterns in high grade serous ovarian cancer. Gynecol Oncol 124: $582-588,2012$ 
79. Widschwendter M, Apostolidou S, Jones AA, Fourkala EO, Arora R, Pearce CL,Frasco MA, Ayhan A,Zikan M, Cibula D, et al: HOXA methylation in normal endometrium from premenopausal women is associated with the presence of ovarian cancer: A proof of principle study. Int J Cancer 125: 2214-2218, 2009.

80. Häfner N, Steinbach D, Jansen L, Diebolder H, Dürst M and Runnebaum IB: RUNX3 and CAMK2N1 hypermethylation as prognostic marker for epithelial ovarian cancer. Int J Cancer 138: 217-228, 2016

81. Deng Z, Wang L, Hou H, Zhou J and Li X: Epigenetic regulation of IQGAP2 promotes ovarian cancer progression via activating Wnt/ $\beta$-catenin signaling. Int J Oncol 48: 153-160, 2016.

82. Prahm KP, Høgdall C, Karlsen MA, Christensen IJ, Novotny GW, Knudsen S, Hansen A, Jensen PB, Jensen T, Mirza MR, et al: Clinical validation of chemotherapy predictors developed on global microRNA expression in the NCI60 cell line panel tested in ovarian cancer. PLoS One 12: e0174300, 2017.

83. Ferrandina G, Fagotti A, Salerno MG, Natali PG, Mottolese M, Maneschi F, De Pasqua A, Benedetti-Panici P, Mancuso S and Scambia G: p53 overexpression is associated with cytoreduction and response to chemotherapy in ovarian cancer. Br J Cancer 81 733-740, 1999.

84. Reles A, Wen WH, Schmider A, Gee C, Runnebaum IB, Kilian U, Jones LA, El-Naggar A, Minguillon C, Schönborn I, et al: Correlation of $\mathrm{p} 53$ mutations with resistance to platinum-based chemotherapy and shortened survival in ovarian cancer. Clin Cancer Res 7: 2984-2997, 2001.

85. Sung HY, Yang SD, Ju W and Ahn JH: Aberrant epigenetic regulation of GABRP associates with aggressive phenotype of ovarian cancer. Exp Mol Med 49: e335, 2017.

86. Sung HY, Yang SD, Park AK, Ju W and Ahn JH: Aberrant hypomethylation of solute carrier family 6 member 12 promoter induces metastasis of ovarian cancer. Yonsei Med J 58: 27-34, 2017.

87. Sung HY, Choi EN, Lyu D, Park AK, Ju W and Ahn JH: Aberrant hypomethylation-mediated AGR2 overexpression induces an aggressive phenotype in ovarian cancer cells. Oncol Rep 32: 815-820, 2014.

88. Sung HY,Park AK, Ju W and Ahn JH: Overexpression of mucin 13 due to promoter methylation promotes aggressive behavior in ovarian cancer cells. Yonsei Med J 55: 1206-1213, 2014.

89. Sung HY, Ju W and Ahn JH: DNA hypomethylation-mediated overexpression of carbonic anhydrase 9 induces an aggressive phenotype in ovarian cancer cells. Yonsei Med J 55: 1656-1663, 2014

90. Zhang W, Barger CJ, Link PA, Mhawech-Fauceglia P, Miller A, Akers SN,OdunsiKand KarpfAR:DNAhypomethylation-mediated activation of Cancer/Testis Antigen 45 (CT45) genes is associated with disease progression and reduced survival in epithelial ovarian cancer. Epigenetics 10: 736-748, 2015.

91. Kohler RS, Anugraham M, López MN, Xiao C, Schoetzau A, Hettich T, Schlotterbeck G, Fedier A, Jacob F and Heinzelmann-Schwarz V: Epigenetic activation of MGAT3 and corresponding bisecting GlcNAc shortens the survival of cancer patients. Oncotarget 7: 51674-51686, 2016.

92. Cardenas H, Vieth E, Lee J, Segar M, Liu Y, Nephew KP and Matei D: TGF- $\beta$ induces global changes in DNA methylation during the epithelial-to-mesenchymal transition in ovarian cancer cells. Epigenetics 9: 1461-1472, 2014.

93. Menon U, Gentry-Maharaj A, Ryan A, Sharma A, Burnell M, Hallett R, Lewis S, Lopez A, Godfrey K, Oram D, et al: Recruitment to multicentre trials-lessons from UKCTOCS: Descriptive study. BMJ 337: a2079, 2008.

94. Piek JM, van Diest PJ,Zweemer RP, Jansen JW, Poort-Keesom RJ, Menko FH, Gille JJ, Jongsma AP, Pals G, Kenemans P and Verheijen RH: Dysplastic changes in prophylactically removed fallopian tubes of women predisposed to developing ovarian cancer. J Pathol 195: 451-456, 2001.

95. Finch A, Shaw P, Rosen B, Murphy J, Narod SA and Colgan TJ: Clinical and pathologic findings of prophylactic salpingo-oophorectomies in 159 BRCA1 and BRCA2 carriers. Gynecol Oncol 100: 58-64, 2006.

96. Kindelberger DW, Lee Y, Miron A, Hirsch MS, Feltmate C, Medeiros F, Callahan MJ, Garner EO, Gordon RW, Birch C, et al: Intraepithelial carcinoma of the fimbria and pelvic serous carcinoma: Evidence for a causal relationship. Am J Surg Pathol 31: 161-169, 2007.
97. Przybycin CG, Kurman RJ, Ronnett BM, Shih IeM and Vang R: Are all pelvic (nonuterine) serous carcinomas of tubal origin? Am J Surg Pathol 34: 1407-1416, 2010.

98. Kuhn E, Kurman RJ, Vang R, Sehdev AS, Han G, Soslow R, Wang TL and Shih IeM: TP53 mutations in serous tubal intraepithelial carcinoma and concurrent pelvic high-grade serous carcinoma-evidence supporting the clonal relationship of the two lesions. J Pathol 226: 421-426, 2012.

99. Perets R, Wyant GA, Muto KW, Bijron JG, Poole BB, Chin KT, Chen JY, Ohman AW, Stepule CD, Kwak S, et al: Transformation of the fallopian tube secretory epithelium leads to high-grade serous ovarian cancer in Brca;Tp53;Pten models. Cancer Cell 24: 751-765, 2013

100. Callahan MJ, Crum CP, Medeiros F, Kindelberger DW, Elvin JA, Garber JE, Feltmate CM, Berkowitz RS and Muto MG: Primary fallopian tube malignancies in BRCA-positive women undergoing surgery for ovarian cancer risk reduction. J Clin Oncol 25: 3985-3990, 2007.

101. Medeiros F, Muto MG, Lee Y, Elvin JA, Callahan MJ, Feltmate C, Garber JE, Cramer DW and Crum CP: The tubal fimbria is a preferred site for early adenocarcinoma in women with familial ovarian cancer syndrome. Am J Surg Pathol 30: 230-236, 2006.

102. Bartlett TE, Chindera K, McDermott J, Breeze CE, Cooke WR, Jones A, Reisel D, Karegodar ST, Arora R, Beck S, et al: Epigenetic reprogramming of fallopian tube fimbriae in BRCA mutation carriers defines early ovarian cancer evolution. Nat Commun 7: 11620, 2016.

103. Doufekas K, Zheng SC, Ghazali S, Wong M, Mohamed Y, Jones A, Reisel D, Mould T, Olaitan A, Macdonald N, et al: DNA methylation signatures in vaginal fluid samples for detection of cervical and endometrial cancer. Int J Gynecol Cancer: Jun 2 , 2016 (Epub ahead of print).

104. Wang Y, Cardenas H, Fang F, Condello S, Taverna P, Segar M, Liu Y, Nephew KP and Matei D: Epigenetic targeting of ovarian cancer stem cells. Cancer Res 74: 4922-4936, 2014

105. Cacan E: Epigenetic-mediated immune suppression of positive co-stimulatory molecules in chemoresistant ovarian cancer cells. Cell Biol Int 41: 328-339, 2017.

106. Yan B, Yin F, Wang QI, Zhang W and Li LI: Integration and bioinformatics analysis of DNA-methylated genes associated with drug resistance in ovarian cancer. Oncol Lett 12: 157-166, 2016.

107. Cacan E: Epigenetic regulation of RGS2 (Regulator of G-protein signaling 2) in chemoresistant ovarian cancer cells. J Chemother 29: 173-178, 2017.

108. Tomar T, Alkema NG, Schreuder L, Meersma GJ, de Meyer T, van Criekinge W, Klip HG, Fiegl H, van Nieuwenhuysen E, Vergote I, et al: Methylome analysis of extreme chemoresponsive patients identifies novel markers of platinum sensitivity in high-grade serous ovarian cancer. BMC Med 15: 116, 2017.

109. Lund RJ, Huhtinen K, Salmi J, Rantala J, Nguyen EV, Moulder R, Goodlett DR, Lahesmaa R and Carpén O: DNA methylation and transcriptome changes associated with cisplatin resistance in ovarian cancer. Sci Rep 7: 1469, 2017.

110. Bonito NA, Borley J, Wilhelm-Benartzi CS, Ghaem-Maghami S and Brown R: Epigenetic regulation of the homeobox gene MSX1 associates with platinum-resistant disease in high-grade serous epithelial ovarian cancer. Clin Cancer Res 22: 3097-3104, 2016.

111. de Leon M, Cardenas H, Vieth E, Emerson R, Segar M, Liu Y, Nephew K and Matei D: Transmembrane protein 88 (TMEM88) promoter hypomethylation is associated with platinum resistance in ovarian cancer. Gynecol Oncol 142: 539-547, 2016.

112. Teschendorff AE, Lee SH, Jones A, Fiegl H, Kalwa M, Wagner W, Chindera K, Evans I, Dubeau L, Orjalo A, et al: HOTAIR and its surrogate DNA methylation signature indicate carboplatin resistance in ovarian cancer. Genome Med 7: 108, 2015.

113. Han X, Zhou Y, You Y, Lu J, Wang L, Hou H, Li J, Chen W, Zhao L and Li X: TET1 promotes cisplatin-resistance via demethylating the vimentin promoter in ovarian cancer. Cell Biol Int 41: 405-414, 2017. 